\title{
Multiple Criteria Human Performance Evaluation Using Choquet Integral
}

\author{
Tuncay GÜRBÜZ* \\ Industrial Engineering Dept., Galatasaray University, \\ Çırağan cad. No. 3634357 Ortaköy, Istanbul, Turkey. \\ Received: 30-10-2009 \\ Accepted: 22-04-2010
}

\begin{abstract}
It is a critical issue for the continuity of an organization to efficiently evaluate the performance of its employees. The evaluation process has to guarantee a sufficient level of objectivity and a limited level of subjectivity in order to answer the employees' expectancies. In this study, a multi-criteria approach to this problem has been proposed since the employees' performance depends on various criteria simultaneously. It is also considered that those criteria may have interaction. Hence, Choquet Integral has been used to handle this situation. To illustrate the use of the proposed method, the performance of a set of employees working in a company in medical sector is evaluated.
\end{abstract}

Keywords: Performance Evaluation (PE); Choquet Integral; MACBETH, Multi-criteria Decision Making (MCDM); Human Resources (HR).

\section{Introduction}

During the last decade, all published articles about Human Resources Management (HRM) and performance assumed the Human Resources (HR) solely as a department, focused on the issues of personnel selection and corporate performance, and disregard capturing the employees' performance evaluation (PE). There have been numerous studies on the following topics: the connection between HRM (as a source of competitive advantage) and the organizational performance ${ }^{1-4}$; the need to develop effective personnel selection mechanism to find the talents who are the most suitable to the organizations ${ }^{5}$; optimizing HR allocation problems with respect to organizational requirements and jobs classification ${ }^{6,7}$; determination of the salary and benefit for the applicants based on their qualifications ${ }^{8}$.

On the other hand, only studies on HR including MCDM tools are as follows and they are mostly focused on personnel allocation: In Ref. 7 Analytic Hierarchy
Process (AHP) is used together with Linear Programming (LP) for HR allocation problem; in Ref. 9 Analytic Network Process (ANP) is used for a PE model for project managers; in Ref. 10 ordered weighted average (OWA) aggregation operators is used for the personnel selection problem; in Ref. 6 a multicriteria ordinal ranking model is used for personnel allocation among branches of a large-scale commercial bank.

In MCDM methods such as AHP, Technique for Order Preference by Similarity to Ideal Solution (TOPSIS) etc., there is the assumption of "independence of the criteria / sub-criteria / alternatives", which is practically erroneous in real life problems. To be able to do such an assumption, one must be sure that there isn't any possible relation between criteria or alternatives according to the data at hand. Otherwise, the final decision may seriously be affected with this assumption.

Evaluating human performance is evidently a MCDM problem. In selecting an optional alternative in an environment of MCDM, different attributes of the alternative are often considered as with quantitative and

*tgurbuz@gsu.edu.tr; tuncaygurbuz09@gmail.com 
qualitative information. Consequently, decision making problems may include preference information in different formats ${ }^{11}$. The originality of this study comes from the multi-criteria approach to the human PE. Also, the fact that criteria may show interactions is not ignored. As opposed to the classical PE tools that exist in the business world, the proposed method considers those interactions between criteria.

The proposed method, namely the Choquet Integral $(\mathrm{CI})^{12}$, has been introduced in the fuzzy measure community by Murofushi and Sugeno ${ }^{13}$. CI is a fuzzy integral and considers the interactions between $k$ out of $n$ criteria of the problem, which is called the $k$-additivity property. The interaction value (positive or negative) of $k$ criteria under consideration will determine if these criteria must all be satisfied at the same time or the satisfaction of only one of them is enough to be considered as a successful or good performing unit. For the sake of simplicity and the applicability to the real life situations as effectively as possible, in this study, the 2-additive CI will be used. Hence, with the explanation given above, a positive interaction between two criteria will show that both of them have to be satisfied and a negative one will show that it's enough that one of the criteria be satisfied by an alternative in order for that alternative to be considered successful. In other words, these cases can be considered as "conjunctive" or "disjunctive" relations between criteria. It has to be noted that in these kinds of interdependencies / interactions, the relations between criteria and alternatives are not mentioned. This is just the relations between criteria in themselves.

The basic matter in CI, is to define the weight of each elementary performance expression in relation to all other contributions to the overall performance, i.e. the Shapley parameters and the interaction parameters of any pair of performance criteria. There are several methods to do that, but in this study one of them, namely Measuring Attractiveness by a Categorical Based Evaluation TecHnique - MACBETH, a multicriteria decision analysis approach which has been proposed by Bana e Costa ${ }^{14}$ will be proposed.

The rest of this paper is organized as follows: Section 2 will mention about PE in HR. Sections 3will give the basics of CI and MACHBETH. Section 4 shows the use of MACBETH in order to find the Shapley and the interaction parameters for 2-additive CI. For a better understanding of the proposed method in HR PE, Section 5 of this study gives an application. Finally the conclusions will be presented in Section 6 .

\section{Performance Evaluation in $\mathbf{H R}$}

$\mathrm{PE}$ is one of the most important fields to analyze for the continuity of an organization. It is also one of the most central HR practices in organizations due to its critical relations with selection, compensation, training and other employment practices ${ }^{15}$. For this challenge, a research area named Strategic Human Resource Management - SHRM, devoted to understand the effects of HRM practices on organization's outcomes $^{16,17}$, has been arisen. Considered by many as the earliest SHRM paper, in Ref. 18, it has been argued that HR activities have a major influence on individual performance and therefore productivity and organizational performance, the cycle of HR activities is interdependent and effective strategic management requires effective HR management.

HR practices that SHRM theorists consider performance enhancing are known as high-performance work practices (HPWPs) ${ }^{19}$ including training, employee participation, flexible work arrangements ${ }^{19,20}$, increasing the employees' knowledge, skills and abilities (KSAs) and encouraging employees to leverage their KSAs for organizational benefit ${ }^{21,22}$ which result in greater job satisfaction, lower employee turnover, higher productivity and better decision making hence improve organizational performance ${ }^{23}$. According to Ref. 24, a statistical aggregation of 92 studies supported the hypothesis of the use of HPWPs is positively related to the organizational performance.

Using relatively large samples of companies and individuals from different sectors, the studies presented in Refs. $25-30$ showed and supported the facts that HR practices have a direct effect on organizational performance, business strategy moderates the relationship between HR practices and organizational performance and successful companies had increased HR involvement in strategic decisions and formalized HR practices.

In Ref. 31, it is argued that employees often perform below their potential because they have arbitrary use of their talent and time. The reasons for them to work have to be strong enough to make them work even if the supervisor turns around and stop watching. In other words, the employees must be motivated to leverage their KSAs. HPWPs such as performance appraisal, internal promotion policies, security, flexible work hours and schedules can help to increase motivation of the employees as stated in Refs. 19, 20, 22 and 32. It has been demonstrated by several studies that encouraging the employees to participate in organizational efforts is important in increasing organizational performance ${ }^{33-35}$. 
The employee performance can remarkably increase with the application of the appropriate HR practices ${ }^{36}$.

For an effective HRM, the enterprise will let the process of evaluation develop itself. Such an enterprise has to build a system which answers the needs of the enterprise as well as those of the individuals. This means the system guarantees enough of objectivity, presents credible stakes of progression and career, simplifies the organization functioning and attach importance to development. To avoid psychological phenomena and answer the expectations of the employees, the evaluation process has to insure a sufficient level of objectivity and only a limited level of subjectivity. Very often, the impossibility of being perfectly objective drives the evaluators to be perfectly subjective, which will lead to the mistrust to their legitimacy. In addition to these, the evaluation process has to be explicit and organized. Therefore it will lay on criteria defined beforehand; it will be elaborated by maintenance and will allow a connection between the evaluation realized and the perspectives of career evolution and rewards offered.

A performance management system must be and keep being practical. If the process becomes heavy, then nobody will want to use it and it will not be useful anymore. If a good system solves a number of problems, then a bad one will create some new ones. Let alone the waste of time and other resources, bad systems have the great risk of not providing the necessary information which will cause the managers confront with very difficult situations and be inefficient to solve the important performance problems. Therefore, the system must be as simple and as less bureaucratic as possible, require a minimum investment of time, offer a maximum level of comfort and answer the needs of the managers, the employees and the enterprise.

\section{Preliminaries}

\subsection{Choquet Integral}

\subsubsection{Definitions}

Definition 3.1.: Let $\mu$ be a non-monotonic fuzzy measure on $X$ and $f$ a function on $X$ with range $\left\{a_{1}, a_{2}, \ldots, a_{n},\right\} \quad$ where $a_{1} \leq a_{2} \leq \cdots \leq a_{n}$. The CI (C) $\int f(x) d \mu(x)$ or simply $(C) \int f d \mu$ of $f$ with respect to $\mu$ is defined as follows:

$$
\begin{gathered}
(C) \int f d \mu=\sum_{i=1}^{n}\left(a_{i}-a_{i-1}\right) \cdot \mu\left(\left\{x \mid f(x) \geq a_{i}\right\}\right), \\
\text { where } a_{0}=0
\end{gathered}
$$

Definition 3.2.: Let $\mu$ be a set function on $X$. The Möbius transform of $\mu$ is a set function on $X$ defined by

$$
m(A)=\sum_{B \subseteq A}(-1)^{|A \backslash B|} \mu(B), \quad \forall A \subseteq X
$$

The transformation is invertible and $\mu$ can be recovered from $m$ by

$$
\mu(A)=\sum_{B \subseteq A} m(B), \quad \forall A \subset X
$$

Here, it has to be noted that surely, any set of $2 n$ coefficients $\{m(T) \mid T \subseteq N\}$ could not be the Möbius representation of a fuzzy measure. The following boundary and the monotonicity conditions must be ensured $^{37}$.

$$
\left\{\begin{array}{l}
m(\emptyset)=0 \\
\sum_{T \subseteq N} m(T)=1 \\
\sum_{T: i \in T \subseteq S} m(T) \geq 0, \quad \forall S \subseteq N, \quad \forall i \in S
\end{array}\right.
$$

Since a fuzzy measure defined on a set of $n$ elements requires $2 n$ real coefficients for its definition, $k$-additive measures have been introduced by Grabisch ${ }^{38}$ in order to decrease the exponential complexity of fuzzy measures in practical applications.

Definition 3.3.: A fuzzy measure $\mu$ is said to be $k$-order additive or $k$-additive if its Möbius transform $m(A)=0$ for any subset $A$ of $X$ such that $|A|>k$, and there exists at least one subset $A$ of $X$ with exactly $k$ elements such that $m(A) \neq 0$.

Therefore, $k$-additive measures can be represented by a limited set of coefficients, at most $\sum_{i=1}^{k}\left(\begin{array}{l}n \\ i\end{array}\right)$ coefficients.

Definition 3.4.: Let $\mu$ be a fuzzy measure on $X$. The Shapley Index for every $i \in X$ is defined by

$$
\Phi_{i}=\sum_{K \subset X \backslash\{i\}} \frac{(n-|K|-1) !|K| !}{n !}[\mu(K \cup\{i\})-\mu(K)]
$$


Note that $\sum_{i=1}^{n} \Phi_{i}=\mu(X)$ as a basic property of the Shapley value.

The Shapley value of $\mu$ is the vector $\Phi(\mu)=\left[\Phi_{1}, \Phi_{2}, \ldots, \Phi_{n}\right]$. The Shapley index can be interpreted as a kind of the weighted average value of the marginal contribution of element $i$ alone in all coalitions. In other words, the Shapley value represents a true sharing of the total amount $\mu(X)$.

The Shapley value is a fundamental concept in game theory expressing the power index ${ }^{39}$. Analogy with the multi-criteria decision making can be made as follows: $X$ being the set of criteria, $\mu(X)$ has the maximal value, being 1 by convention. The Shapley index expresses the relative importance of a single criterion into the decision problem. The fact that the Shapley value for the criterion, $\Phi_{i}$, is different than $\mu(\{i\})$ is a proof for the interaction of the criteria.

Considering a pair $\{i, j\} \subset N$, the quantity $m(\{i, j\})=\mu(\{i, j\})-\mu(\{i\})-\mu(\{j\})$ seems to define the degree of interaction between $i$ and $j$. The difference will be zero when there will be no interaction, positive if there is a synergy effect and negative when there is a negative interference between $i$ and $j$. But to see the proper interaction between $i$ and $j$, not only $\mu(\{i\}), \mu(\{j\})$ and $\mu(\{i, j\})$ but also all the subsets containing $i$ and $j$ should be considered. That is $\forall K \subset N \backslash\{i, j\}$ :

$$
\mu(K \cup\{i, j\})-\mu(K \cup\{i\})-\mu(K \cup\{j\})+\mu(K)
$$

In Ref. 40, based on considerations of multi-attribute utility theory, the following definition has been proposed to reflect the above discussion.

Definition 3.5.: Let $\mu$ be a fuzzy measure on $X$. The interaction index between the elements $i$ and $j$ of $X$ is defined by:

$$
I_{i j}=\sum_{K \subset M\{\{i, j\}} \frac{(n-|K|-2) !|K| !}{(n-1) !}\left[\begin{array}{l}
\mu(K \cup\{i, j\})-\mu(K \cup\{i\}) \\
-\mu(K \cup\{j\})+\mu(K)
\end{array}\right]
$$

This definition can be enlarged to any coalition as done by Grabisch in Ref. 38 as follows:

$$
I(A)=\sum_{K \subset M \backslash A} \frac{(n-|K|-|A|) !|K| !}{(n-|A|+1) !} \sum_{C \subset A}(-1)^{|\mathrm{A}| \mathrm{C} \mid} \mu(C \cup K)
$$

Similarly, as in $m(\{i, j\})$, if $I_{i j}$ is positive (resp. negative) then the interaction between $i$ and $j$ is said to be positive (resp. negative).

\subsubsection{The 2-order model}

This section will focus on the 2-order additivity which seems to be the most interesting in practical applications since it allows modeling the interactions between criteria while remaining simple.

It requires only $n+\left(\begin{array}{l}n \\ 2\end{array}\right)=\frac{n(n+1)}{2}$ coefficients to define the fuzzy measure as follows:

$$
\begin{gathered}
\mu(i)=m(i), \quad i \in N \\
\mu(\{i, j\})=m(\{i\})+m(\{j\})+m(\{i, j\}), \quad\{i, j\} \subseteq N
\end{gathered}
$$

The other coefficients are given by:

$$
\mu(S)=\sum_{i \in S} m(i)+\sum_{\{i, j\} \subseteq S} m(\{i, j\}), \quad S \subseteq N, \quad|S| \geq 2
$$

Letting $t_{i}, \quad i=1, \ldots, n$ be the scores on the criteria, by using only the interaction index, it is possible to express $\mathrm{CI}$ in the case of 2-additive measures as follows:

$$
\begin{aligned}
C_{\mu}\left(t_{1}, \ldots, t_{n}\right) & =\sum_{I_{i j}>0}\left(t_{i} \wedge t_{j}\right) I_{i j}+\sum_{I_{i j}<0}\left(t_{i} \vee t_{j}\right)\left|I_{i j}\right| \\
& +\sum_{i=1}^{n} t_{i}\left(\Phi_{i}-\frac{1}{2} \sum_{j \neq i}\left|I_{i j}\right|\right)
\end{aligned}
$$

With $\quad \Phi_{i}-\frac{1}{2} \sum_{j \neq i}\left|I_{i j}\right| \geq 0, \quad \forall i=1, \ldots, n$

Note that the CI for 2-additive measures can be decomposed in a conjunctive, a disjunctive and an additive part, corresponding respectively to positive and negative interactions and Shapley values ${ }^{41}$. In the CI framework:

- Positive values of $I_{i j}$ implies a conjunctive behavior between criteria $i$ and $j$. i.e. simultaneous satisfaction of both criteria is significant for the global score.

- Negative values of $I_{i j}$ implies a disjunctive behavior between criteria $i$ and $j$. i.e. the satisfaction of either one of them is sufficient to have a significant effect on the global score. 
- The Shapley value acts as a weight vector in a weighted arithmetic mean. This represents the linear part of $\mathrm{CI}$.

In the 2-order case, the Shapley indices are assumed to be zero for the subsets of at least three elements. Therefore, in terms of the Möbius transformation the CI becomes:

$$
C_{\mu}(x)=\sum_{i \in N} m(i) x_{i}+\sum_{\{i, j\} \subseteq N} m(\{i, j\})\left(x_{i} \wedge x_{j}\right), \quad x \in \mathfrak{R}^{n}
$$

\section{2. МАCBETH}

Measuring Attractiveness by a Categorical Based Evaluation TecHnique - MACBETH is a multi-criteria decision analysis approach which has been proposed in Refs. 14, $42-44$. MACBETH has been used in various fields such as individual's career choice ${ }^{45}$, evaluation and comparison of the technical performance of onboard hydrogen storage technologies ${ }^{46}$, politics ${ }^{47}$, supply chain management $^{48}$, earthquake risk mitigation ${ }^{49}$.

The method requires only qualitative judgments about differences of value to help an individual or a group in quantifying the relative attractiveness of the elements of a finite set $A$ and to associate a real number $v(x)$ to each element $x$ of $A^{50}$.

Let $X$ be the finite set of elements (alternatives) with at least two elements and $J$ the group of decision makers (DMs) who want to compare the relative attractiveness of these elements. Here, it is assumed that the DM or each DM is able to rank the elements of $X$ either directly or through pairwise comparisons. Each DM is first asked to provide a judgment about the relative attractiveness of two elements at a time to retrieve the ordinal judgment. Then secondly, he is asked to provide a qualitative judgment on the difference of attractiveness of those two elements if they are not equally attractive. In order to ease the process, the following six semantic categories of difference of attractiveness (or a succession of these if the DM hesitates) are offered to the DMs as possible answers:

- Very weak

- Weak

- Moderate

- Strong

- Very strong

- Extreme

The principle of the method is to transform the qualitative data, which is always available due to the human expertise and which is collected from the DMs, into the quantitative data. But in the performance aggregation procedure, the elementary performance values must respect the commensurability requirement and be coherent with the chosen aggregation operator, generally the weighted mean. The MACBETH method, presents a procedure to transform qualitative preferences into coherent quantified elementary and aggregated performances. To solve the inter-criteria commensurability problem, it is sufficient to determine, for all interval scales, two common reference points namely the good situation and the neutral situation with the performance values 1 and 0 respectively.

\subsubsection{The MACBETH procedure}

The MACBETH Procedure consists in four main steps $^{51}$ :

(i) Context definition.

(ii) Identification of the objective, criteria and alternatives.

(iii) Quantify in parallel:

(a) the vector of elementary expressions. (Step 2)

(b) the weights of the weighted arithmetic mean (WAM). (Step 3)

(iv) Calculate the aggregated performance associated to different situations (alternatives).

The verification of judgments' consistency is made in the second and third steps. The elementary performance expression step is made in two stages. In the first one, the DMs are asked to determine the preferences of the alternatives for each criterion $i$ of the context and in the following stage, they are asked to express the strength of the judgments he provided in the previous stage.

\subsubsection{Identification of elementary performance expression with MACBETH}

Let $p_{i}^{k}$ be the performance expression of the $k$ th alternative for criterion $i$. Suppose the DM prefers for criterion $i$ the alternative $k$ to the alternative $l$, therefore, it will mean: $A^{k} \succ A^{l} \Leftrightarrow p_{i}^{k}>p_{i}^{l}$. And if the DM finds the two alternatives are equivalent for the criterion $i$, then $A^{k} \approx A^{l} \Leftrightarrow p_{i}^{k}=p_{i}^{l}$.

In addition to that information, DM will characterize the strength of his judgments with a level of strength that can take values from one to six (from the least to the most strong level) according to the six semantic categories of difference of attractiveness explained above and zero for a null strength. This level will be denoted with $h$. Therefore, if the DM prefers for 
criterion $i$ the alternative $k$ to the alternative $l$, with a strength $h$, then the following equation where $\alpha$ is a coefficient necessary to meet the condition and $p^{k}$ and $p^{l} \in[0 ; 1]$ will be obtained:

$$
A^{k} \succ^{h} A^{l} \Leftrightarrow p_{i}^{k}-p_{i}^{l}=h \alpha
$$

Example: Suppose that the DM gives the following preferences and the strength of preferences for three alternatives according to some criterion:

$$
\text { Good } \succ^{3} A^{3} \succ^{2} A^{2} \succ^{1} A^{1} \succ^{2} \text { Neutral }
$$

Therefore, the following system of independent equations is obtained:

$$
\left\{\begin{array}{l}
p^{\text {Good }}-p^{3}=1-p^{3}=3 \alpha \\
p^{3}-p^{2}=2 \alpha \\
p^{2}-p^{1}=\alpha \\
p^{1}-p^{\text {Neutral }}=p^{1}-0=2 \alpha
\end{array}\right.
$$

Hence the following results of the elementary performance expressions are defined along interval scales defined on the interval $[0 ; 1]$ in a commensurate way $^{51}$ :

$$
p^{1}=\frac{1}{4}, \quad p^{2}=\frac{3}{8}, \quad p^{3}=\frac{5}{8}, \quad\left(\alpha=\frac{1}{8}\right)
$$

\subsubsection{WAM weights determination}

As for the elementary performance expressions, in order to do that, MACBETH proposes to consider some particular and possibly fictive situations, $S$, in which are associated the elementary expression vectors so that the aggregated performance expression is reduced simply to $p_{A g}^{i}=w_{i}$ where $p_{A g}^{i}$ is the aggregated performance from the vector where $p_{i}=1$ and all other $p_{j}=0$ with $j \neq i$. The DM will give the preference relations and their strengths. Each one of them will be as follows and all together they will provide a system of $n$ independent equations:

$$
p_{A g}^{i}-p_{A g}^{g}=h \alpha=w_{i}-w_{g}
$$

Example: Suppose that the DM provided the following information:

$$
S^{(0,1,0)} \succ^{\text {moderate }} S^{(1,0,0)} \succ^{\text {strong }} S^{(0,0,1)} \succ^{\text {weak }} S^{(0,0,0)}
$$

Hence this gives the following system of equations and the WAM weights:

$$
\begin{gathered}
\left\{\begin{array}{l}
p_{A g}^{(0,0,1)}-p_{A g}^{(1,0,0)}=3 \alpha=w_{2}-w_{1} \\
p_{A g}^{(1,0,0)}-p_{A g}^{(0,1,0)}=4 \alpha=w_{1}-w_{3} \\
p_{A g}^{(0,1,0)}-p_{A g}^{(0,0,0)}=2 \alpha=w_{3} \\
w_{1}+w_{2}+w_{3}=1
\end{array}\right. \\
w_{1}=\frac{6}{17}, \quad w_{2}=\frac{9}{17}, \quad w_{3}=\frac{2}{17}, \quad\left(\alpha=\frac{1}{17}\right)
\end{gathered}
$$

\subsubsection{The aggregated performance}

The aggregated performance of the alternative situation $\mathrm{k}$ is calculated as follows:

$$
p_{A g}^{k}=\sum_{i=1}^{n} w_{i} p_{i}^{k}
$$

\section{MACBETH \& 2-additive CI}

In this section, the calculations of the weight of each elementary performance expression in relation to all other contributions to the overall performance, i.e. the Shapley parameters $v_{i}$ and the interaction parameters $I_{i j}$ of any pair of performance criteria will be explained. In the case of performance expression, the 2-additive CI expression given in Eq. (11) is represented as follows:

$$
p_{\text {Total }}=\sum_{i=1}^{n} v_{i} p_{i}+\frac{1}{2} \sum_{\substack{\{i, j\} \\ i \neq j}} I_{i j}\left|p_{i}-p_{j}\right|
$$

$$
\text { where } v_{i}-\frac{1}{2} \sum_{j=1}^{n}\left|I_{i j}\right| \geq 0 \quad \forall i \in[1, n] \text { and } j \neq i
$$

The elementary performance expressions are defined as it is explained in the section (3.2.2). So the CI parameters have to be defined. In order to do that, the DM is asked to provide preferential information on the criteria and the couples of criteria including the strength of the preferences. This information will help us to build a system of equations with the Shapley and the Interaction parameters as variables.

As in section (3.2.3), in the situations where only one $p_{i}=1$ and all others are equal to zero, the aggregated performance expression will be as follows:

$$
p_{A g}^{i}=v_{i}-\frac{1}{2} \sum_{\substack{j=1 \\ j \neq i}}^{n} I_{i j}
$$


Note that if there is no interaction between criteria, $I_{i j}=0 \quad \forall i, j \in \aleph_{1 ; n}$ and therefore, $p_{A g}^{i}=v_{i}$, in other words WAM weights.

The aggregated performance expression of the situations where only one $p_{i}=0$ and all others are equal to one will be as follows:

$$
p_{A g}^{i}=1-v_{i}-\frac{1}{2} \sum_{\substack{j=1 \\ j \neq i}}^{n} I_{i j}
$$

The aggregated performance expression of the situations where only two elementary performance expressions are equal to one $p_{i}=1$ and $p_{j}=1$ all others are equal to zero will be as follows:

$$
p_{A g}^{i, j}=v_{i}+v_{j}-\frac{1}{2}\left(\sum_{k \in \mathbb{N}_{i ; n} \mid p_{k}=0} I_{i k}+\sum_{k \in \aleph_{i ; n} \mid p_{k}=0} I_{j k}\right)
$$

\section{Application}

\subsection{Problem definition}

To analyze the use of the proposed method, the performance of a set of employees working in a company in medical sector will be evaluated.

The company produces infusion sets, i.e. the equipment to inject serum from the bottle to the patient's arm. In the production area, there are six different task stations that you can see below, hence, six different groups of employees to do these tasks:

- Assembling Needle - Adaptor - "AI"

- Assembling Flashtube - Adaptor - "AF"

- Assembling Needle + Flash tube - Pipe E5 - "EF"

- Assembling of Dropping group - Pipe E5 - "ED"

- Putting the set in the bag and Sealing - "S" and

- Packaging - "K"

For sake of simplicity, the calculations for only one of the following groups, namely Assembling Flashtube Adaptor - AF in which five employees are working, will be detailed to show how the model works. The purpose is to determine the best performing employee along with a performance ranking of all employees working for this group. For this company, this determination depends on the following criteria:

- $\quad$ productivity $(\mathrm{C} 1)$,

- $\quad$ absence (C2),
- $\quad$ hygiene (C3),

- $\quad$ education level (C4) and

- characteristic properties (C5).

\subsection{Determination of WAM weights}

The DM gave the following information on alternatives for each criterion, i.e. the pre-order according to his expertise including the strength of his/her preference:

$$
\begin{aligned}
& C 1 \Rightarrow \text { good } \succ^{1} A 2 \succ^{4} A 3 \succ^{3} A 5 \succ^{4} A 1 \succ^{4} A 4 \succ^{1} \text { neutral } \\
& C 2 \Rightarrow \text { good } \succ^{3} A 3 \succ^{1} A 4 \succ^{1} A 1 \succ^{1} A 5 \succ^{2} A 2 \succ^{2} \text { neutral } \\
& C 3 \Rightarrow \text { good } \succ^{2} A 1 \succ^{3} A 2 \succ^{3} A 4 \succ^{2} A 3 \succ^{2} A 5 \succ^{1} \text { neutral } \\
& C 4 \Rightarrow \text { good } \succ^{2} A 2 \succ^{3} A 4 \succ^{3} A 5 \succ^{2} A 3 \succ^{2} A 1 \succ^{1} \text { neutral } \\
& C 5 \Rightarrow \text { good } \succ^{3} A 1 \succ^{1} A 2 \succ^{1} A 5 \succ^{3} A 3 \succ^{2} A 4 \succ^{1} \text { neutral }
\end{aligned}
$$

From this preferential information, using Eq. (13), the following equation systems and solutions have been found:

$$
\begin{aligned}
& \begin{array}{l|l}
1-p^{2}=\alpha \\
p^{2}-p^{3}=4 \alpha \\
\left.\left.\begin{array}{l}
p^{3}-p^{5}=3 \alpha \\
p^{5}-p^{1}=4 \alpha \\
p^{1}-p^{4}=4 \alpha \\
p^{4}-0=\alpha
\end{array}\right\} \begin{array}{l}
p^{4}=\alpha \\
p^{1}=5 \alpha \\
p^{5}=9 \alpha \\
p^{3}=12 \alpha \\
p^{2}=16 \alpha \\
1=17 \alpha \Leftrightarrow \alpha=\frac{1}{17}
\end{array}\right\} p^{5}=5 / 17 \\
p^{2}=16 / 17 \\
p^{3}=12 / 17 \\
p^{4}=1 / 17
\end{array} \\
& \left.\left.\begin{array}{l|l}
1-p^{3}=3 \alpha \\
p^{3}-p^{4}=\alpha \\
p^{4}-p^{1}=\alpha \\
p^{1}-p^{5}=2 \alpha \\
p^{5}-p^{2}=2 \alpha \\
p^{2}-0=2 \alpha
\end{array}\right\} \begin{array}{l}
p^{2}=2 \alpha \\
p^{5}=4 \alpha \\
p^{1}=6 \alpha \\
p^{4}=7 \alpha \\
p^{3}=8 \alpha \\
1=11 \alpha \Leftrightarrow \alpha=\frac{1}{11}
\end{array}\right\} \begin{array}{l}
p^{1}=6 / 11 \\
p^{2}=2 / 11 \\
p^{3}=8 / 11 \\
p^{4}=7 / 11 \\
p^{5}=4 / 11
\end{array} \\
& \left.\left.\begin{array}{l|l}
1-p^{1}=2 \alpha \\
p^{1}-p^{2}=3 \alpha \\
p^{2}-p^{4}=3 \alpha \\
p^{4}-p^{3}=2 \alpha \\
p^{3}-p^{5}=2 \alpha \\
p^{5}-0=\alpha
\end{array}\right\} \begin{array}{l}
p^{5}=\alpha \\
p^{3}=3 \alpha \\
p^{4}=5 \alpha \\
p^{2}=8 \alpha \\
p^{1}=11 \alpha \\
1=13 \alpha \Leftrightarrow \alpha=\frac{1}{13}
\end{array}\right\} \begin{array}{l}
p^{1}=11 / 13 \\
p^{2}=8 / 13 \\
p^{3}=3 / 13 \\
p^{4}=5 / 13 \\
p^{5}=1 / 13
\end{array}
\end{aligned}
$$

$$
\left.\left.\begin{array}{l|l}
1-p^{2}=2 \alpha \\
p^{2}-p^{4}=3 \alpha \\
p^{4}-p^{5}=3 \alpha \\
p^{5}-p^{3}=2 \alpha \\
p^{3}-p^{1}=2 \alpha \\
p^{1}-0=\alpha
\end{array}\right\} \begin{array}{l}
p^{1}=\alpha \\
p^{3}=3 \alpha \\
p^{5}=5 \alpha \\
p^{4}=8 \alpha \\
p^{2}=11 \alpha \\
1=13 \alpha \Leftrightarrow \alpha=\frac{1}{13}
\end{array}\right\} \begin{aligned}
& p^{1}=1 / 13 \\
& p^{2}=11 / 13 \\
& p^{3}=3 / 13 \\
& p^{4}=8 / 13 \\
& p^{5}=5 / 13
\end{aligned}
$$




$$
\left.\left.\begin{array}{l|l|l}
1-p^{1}=3 \alpha & p^{4}=\alpha \\
p^{1}-p^{2}=\alpha & p^{3}=3 \alpha \\
p^{2}-p^{5}=\alpha & p^{5}=6 \alpha \\
p^{5}-p^{3}=3 \alpha & p^{3}-p^{4}=2 \alpha \\
p^{4}-0=1 \alpha
\end{array}\right\} \begin{array}{l}
p^{2}=8 / 11 \\
p^{1}=8 \alpha \\
1=11 \alpha \Leftrightarrow \alpha=\frac{1}{11}
\end{array}\right\} \begin{aligned}
& p^{2}=7 / 11 \\
& p^{3}=3 / 11 \\
& p^{4}=1 / 11 \\
& p^{5}=6 / 11
\end{aligned}
$$

Therefore, the performance values for the alternatives with respect to the problem's criteria are as indicated in the following table:

Table 5.1. Alternatives performance values with respect to problem's criteria

\begin{tabular}{l|lllll} 
& C1 & C2 & C3 & C4 & C5 \\
\hline A1 & 0.294 & 0.545 & 0.846 & 0.077 & 0.727 \\
A2 & 0.941 & 0.182 & 0.615 & 0.846 & 0.636 \\
A3 & 0.706 & 0.727 & 0.231 & 0.231 & 0.273 \\
A4 & 0.059 & 0.636 & 0.385 & 0.615 & 0.091 \\
A5 & 0.529 & 0.363 & 0.077 & 0.385 & 0.545 \\
\hline
\end{tabular}

\subsection{Determination of criteria weights and interactions}

In order to determine the Shapley and Interaction parameters, $\Phi_{i} \quad i=1, \ldots, 5$ and $I_{i j}$ with $i=1, \ldots, 5$, $j=1, \ldots, 5$ and $i \neq j$ for the criteria, the DM is asked to give his preferential information about criteria of the problem and the ordering with the strength of preferences are collected as follows:

$$
\begin{aligned}
& C 1 \& C 3 \succ^{2} C 2 \& C 3 \succ^{1} C 1 \& C 2 \succ^{2} C 3 \& C 5 \succ^{2} \\
& C 3 \& C 4 \succ^{2} C 1 \& C 5 \succ^{2} C 1 \& C 4 \succ^{1} C 2 \& C 5 \succ^{2} \\
& C 2 \& C 4 \succ^{1} C 4 \& C 5 \succ^{0} C 3 \succ^{2} C 1 \succ^{3} C 5 \succ^{1} C 4 \succ^{1} \\
& C 2 \succ^{2} 0^{\prime \prime}
\end{aligned}
$$

Using Eqs. (17), (18) and (19), the equation system given on the right hand side of this page is obtained. Therefore, letting $A$ be the matrix of the coefficients for the equation system, $V$ the column matrix of variables, namely the Shapley and interaction parameters and $\alpha$, and $e_{i}$ the column vector where all the elements except $i$ th is null, will give the matrix operation below (which is also represented right after the equation system):

$$
A \times V=e_{16}
$$

$$
\left\{\begin{array}{l}
v_{1}-v_{2}-\frac{1}{2}\left(I_{14}+I_{15}+I_{23}-I_{13}-I_{24}-I_{25}\right)=2 \alpha \\
v_{3}-v_{1}-\frac{1}{2}\left(I_{12}+I_{34}+I_{35}-I_{14}-I_{15}-I_{23}\right)=\alpha \\
v_{1}+v_{2}-v_{3}-v_{5}-\frac{1}{2}\left(I_{14}+I_{24}-I_{34}-I_{45}\right)=2 \alpha \\
v_{5}-v_{4}-\frac{1}{2}\left(I_{15}+I_{25}+I_{34}-I_{14}-I_{24}-I_{35}\right)=2 \alpha \\
v_{3}+v_{4}-v_{1}-v_{5}-\frac{1}{2}\left(I_{23}+I_{24}-I_{12}-I_{25}\right)=2 \alpha \\
v_{5}-v_{4}-\frac{1}{2}\left(I_{14}+I_{25}+I_{35}-I_{15}-I_{24}-I_{34}\right)=2 \alpha \\
v_{1}+v_{4}-v_{2}-v_{5}-\frac{1}{2}\left(I_{13}+I_{34}-I_{23}-I_{35}\right)=\alpha \\
v_{5}-v_{4}-\frac{1}{2}\left(I_{15}+I_{24}+I_{35}-I_{14}-I_{25}-I_{34}\right)=2 \alpha \\
v_{2}-v_{5}-\frac{1}{2}\left(I_{23}+I_{45}+I_{12}-I_{15}-I_{24}-I_{35}\right)=\alpha \\
v_{4}+v_{5}-v_{3}-\frac{1}{2}\left(I_{14}+I_{15}+I_{24}+I_{25}-I_{13}-I_{23}\right)=0 \\
v_{3}-v_{1}-\frac{1}{2}\left(I_{23}+I_{34}+I_{35}-I_{12}-I_{14}-I_{15}\right)=2 \alpha \\
v_{1}-v_{5}-\frac{1}{2}\left(I_{12}+I_{13}+I_{14}-I_{25}-I_{35}-I_{45}\right)=3 \alpha \\
v_{5}-v_{4}-\frac{1}{2}\left(I_{15}+I_{25}+I_{35}-I_{14}-I_{24}-I_{34}\right)=\alpha \\
v_{4}-v_{2}-\frac{1}{2}\left(I_{14}+I_{34}+I_{45}-I_{12}-I_{23}-I_{25}\right)=\alpha \\
v_{2}-\frac{1}{2}\left(I_{12}+I_{23}+I_{24}+I_{25}\right)=2 \alpha \\
v_{1}+v_{2}+v_{3}+v_{4}=1
\end{array}\right.
$$$$
\left[\begin{array}{cccccccccccccccc}
1 & -1 & 0 & 0 & 0 & 0 & .5 & -.5 & -.5 & -.5 & .5 & .5 & 0 & 0 & 0 & -2 \\
-1 & 0 & 1 & 0 & 0 & -.5 & 0 & .5 & .5 & .5 & 0 & 0 & -.5 & -.5 & 0 & -1 \\
1 & 1 & -1 & 0 & -1 & 0 & 0 & -.5 & 0 & 0 & -.5 & 0 & .5 & 0 & .5 & -2 \\
0 & 0 & 0 & -1 & 1 & 0 & 0 & .5 & -.5 & 0 & .5 & -.5 & -.5 & .5 & 0 & -2 \\
-1 & 0 & 1 & 1 & -1 & .5 & 0 & 0 & 0 & -.5 & -.5 & .5 & 0 & 0 & 0 & -2 \\
v_{1} \\
0 & 0 & 0 & -1 & 1 & 0 & 0 & -.5 & .5 & 0 & .5 & -.5 & .5 & -.5 & 0 & -2 \\
v_{3} \\
v_{4} \\
v_{5} \\
I_{12} \\
0 & -1 & 0 & 1 & -1 & 0 & -.5 & 0 & 0 & .5 & 0 & 0 & -.5 & .5 & 0 & -1 \\
0 & 1 & 0 & 0 & -1 & -.5 & 0 & 0 & .5 & -.5 & .5 & 0 & 0 & .5 & -.5 & -1 \\
I_{13} \\
0 & 0 & -1 & 1 & 1 & 0 & .5 & -.5 & -.5 & .5 & -.5 & -.5 & 0 & 0 & 0 & 0 \\
-1 & 0 & 1 & 0 & 0 & .5 & 0 & .5 & .5 & -.5 & 0 & 0 & -.5 & -.5 & 0 & -2 \\
1 & 0 & 0 & 0 & -1 & -.5 & -.5 & -.5 & 0 & 0 & 0 & .5 & 0 & .5 & .5 & -3 \\
0 & 0 & 0 & -1 & 1 & 0 & 0 & .5 & -.5 & 0 & .5 & -.5 & .5 & -.5 & 0 & -1 \\
0 & -1 & 0 & 1 & 0 & .5 & 0 & -.5 & 0 & .5 & 0 & .5 & -.5 & 0 & -.5 & -1 \\
0 & 1 & 0 & 0 & 0 & -.5 & 0 & 0 & 0 & -.5 & -.5 & -.5 & 0 & 0 & 0 & -2 \\
1 & 1 & 1 & 1 & 1 & 0 & 0 & 0 & 0 & 0 & 0 & 0 & 0 & 0 & 0 & 0 \\
I_{15} \\
I_{23} \\
I_{24} \\
I_{25} \\
I_{34} \\
I_{35} \\
I_{45} \\
\alpha
\end{array}\right]=\left[\begin{array}{l}
0 \\
0 \\
0 \\
0 \\
0 \\
0 \\
0 \\
0 \\
0 \\
0 \\
0 \\
0 \\
0 \\
0 \\
0 \\
0 \\
0 \\
0
\end{array}\right]
$$

\subsection{Results}

The solution of the matrix operation and the aggregated performance value, calculated using Eq. (16), are presented in Table 5.2.

Hence the final ranking of the alternatives will be:

$$
A 2 \succ A 5 \succ A 3 \succ A 1 \succ A 4
$$

Table 5.2. Aggregated performance of the alternatives 


\begin{tabular}{c|ccccc|c} 
& $\mathrm{C} 1$ & $\mathrm{C} 2$ & $\mathrm{C} 3$ & $\mathrm{C} 4$ & $\mathrm{C} 5$ & $p_{A g}$ \\
\hline \multirow{2}{*}{$A 1$} & 0.294 & 0.545 & 0.846 & 0.077 & 0.727 & 0.172 \\
$A 2$ & 0.941 & 0.182 & 0.615 & 0.846 & 0.636 & 0.336 \\
$A 3$ & 0.706 & 0.727 & 0.231 & 0.231 & 0.273 & 0.205 \\
$A 4$ & 0.059 & 0.636 & 0.385 & 0.615 & 0.091 & 0.045 \\
$A 5$ & 0.529 & 0.363 & 0.077 & 0.385 & 0.545 & 0.218 \\
\hline \multirow{2}{*}{$v_{i}$} & 0.2467 & 0.219 & 0.2829 & 0.1049 & 0.1465 & \\
\hline \multirow{4}{*}{$I_{i j}$} & $I_{12}$ & $I_{13}$ & $I_{14}$ & $I_{15}$ & $I_{23}$ & \\
\cline { 2 - 6 } & 0.124 & 0.033 & 0 & 0.0024 & 0.0855 & \\
\cline { 2 - 5 } & $I_{24}$ & $I_{25}$ & $I_{34}$ & $I_{35}$ & $I_{45}$ & \\
\cline { 2 - 5 } & 0.0132 & 0.041 & 0.0024 & 0.0055 & -0.007 &
\end{tabular}

\section{Concluding Remarks}

The overall objective of the problem is to determine the best performing employee. Here, whole problem has been analyzed and the interactions among the different factors have been taken into account. The most important criteria for the $\mathrm{DM}$ turned out to be $\mathrm{C} 3$ whereas the least important was C4.

During the analysis of this problem, it was visible that it requires a model capable of consisting all the criteria and the interactions between them. From the preference ordering of the criteria and the strength of that preference order given us by the DM, it was concluded that there were interactions, some of which cannot be ignored, between criteria as it can be observed in Table 5.2 .

Positive interaction values as for $\mathrm{C} 1$ and $\mathrm{C} 2$ showed that for the DM an employee must be successful from both these criteria in order to be considered successful. On the other hand negative interaction values such as for C4 and C5 showed that it was enough for an employee to be successful from only one of these criteria to be considered successful by the DM. A null interaction value as for $\mathrm{C} 1$ and $\mathrm{C} 4$ was meaning that there was no interaction between those criteria for the DM. Finally, according to the final ranking found the best performing and the worst performing employees are A2 and A4 respectively.

If the interactions between the problem's criteria were ignored, and the weighted arithmetic mean was used instead, with simple calculations it can be found that the final ranking would be as given below.

$$
A 2 \succ A 1 \succ A 3 \succ A 5 \succ A 4
$$

As it can be observed, the ranking changes compared to the one found in the previous section. The best and worst performing employees didn't change but this fact doesn't guarantees that it will be the same way all the time.

Therefore, in this study, a real life MCDM problem with interactions among criteria is presented and the importance of considering those interactions between the criteria which may clearly be effective in the decision making process is underlined.

For further research, it is suggested that more complex networks should be analyzed with the proposed method: First the interactions among sub-criteria under each criterion, in other words inner-interactions, then the interactions between sub-criteria of one criterion with sub-criteria of another has to be handled in order to solve the cases where there are more complex network structure.

On the other hand, as in the 360-Degree PE model which can be cited as a good example, which became very popular in the last decade, most of the time employees' PE is a group decision making process. Decision making for a complex and/or delicate situations often needs a team to work cooperatively to get consensus awareness for the situation ${ }^{52}$. Therefore, a group decision work of the presented model can also be analyzed.

\section{References}

1. P. Alleyne, L. Doherty and D. Grenidge, Human resource management and performance in the Barbados hotel industrty, Hospitality Management 25 (2006) 623-646.

2. Z. Hussain, J. Wallace and N. E. Cornelius, The use and impact of human resource information systems on human resource management professionals, Information \& Management 44 (2007) 74-89.

3. E. T. Stavrou, C. Charalambous and S. Spiliotis, Human resource management and performance: A neural network analysis, European Journal of Operational Research 181 (2007) 453-467.

4. F. Afiouni, Human resource management and knowledge management: A road map toward improving organizational performance, Journal of American Academy of Business, Cambridge 11(2) (2007) 124-130.

5. C.-F. Chien and L.-F. Chen, Data mining to improve personnel selection and enhance human capital: A case study in high-technology industry, Expert Systems with Applications 34 (2008) 280-290.

6. F. Aleskerov, H. Ersel and R. Yolalan, Personnel allocation among bank branches using a two-stage multicriterial approach, European Journal of Operational Research 148 (2003) 116-125.

7. T. L. Saaty, K. Peniwati and J. S. Shang, The analytic hierarchy process and human resource allocation: Half the story, Mathematical and Computer Modelling 46 (2007) 1041-1053. 
8. M. S. Mehrabad and M. F. Brojeny, The development of an expert system for effective selection and appointment of the jobs applicants in human resource management, Computers \& Industrial Engineering 53 (2007) 306-312.

9. S. H. Chen and H. T. Lee, Performance evaluation model for project managers using managerial practices, International Journal of Project Management 25 (2007) 543-551.

10. L. Canos and V. Liern, Soft computing-based aggregation methods for human resources management, European Journal of Operational Research 189 (2008) 669-681.

11. X. Li, D. Ruan, J. Liu and Y. Xu, A linguistic-valued weighted aggregation operator to multiple attribute group decision making with quantitative and qualitative information, International Journal of Computational Intelligence Systems 1(3) (2008) 274-284.

12. G. Choquet, Theory of capacities, Annales de l'Institut Fourier vol.5 (1953) pp. 131-295.

13. T. Murofushi and M. Sugeno, An interpretation of fuzzy measure and the Choquet integral as an integral with respect to a fuzzy measure, Fuzzy Sets Systems 29 (1989) 201-227.

14. C. A. Bana e Costa, Structuration, construction et exploitation d'un modèle à multi-critère d'aide à la décision, PhD Thesis (Technical University of Lisbon, Lisbon, 1992).

15. G. R. Ferris, T. P. Munyon, K. Basik and M. R. Buckley, The performance evaluation context: Social, emotional, cognitive, political and relationship components, Human Resource Management Review 18 (2008) 146 - 163.

16. G. R. Ferris, W. A. Hochwarter, M. R. Buckley, G. Harrell-Cook and D. D. Frink, Human resource management: Some new directions, Journal of Management 25 (1999) 385-415.

17. I. C. MacMillian and R. S. Schuler, Gaining a competitive edge through human resources, Personnel 62 (1985) 2429

18. N. Tichy, C. Fombrun and M. Devanna, Strategic human resource management, Sloan Management Review 23(2) (1982) 47-61.

19. M. A. Huselid, The impact of human resource management practices on turnover, productivity, and corporate financial performance, Academy of Management Journal 38 (1995) 635-672.

20. J. Pfeffer, Seven practices of successful organizations, California Management Review 40 (1998) 96-124.

21. B. E. Becker and M. A. Huselid, High performance work systems and firm performance: A synthesis of research and managerial implications, in Research in personnel and human resources management, ed. G. R. Ferris (Stamford, CT: JAI Press, 1998) Vol. 16 pp. 53-101.

22. J. E. Delery and J. D. Shaw, The strategic management of people in work organizations: Review, synthesis, and extension, in Research in personnel and human resources management, ed. G. R. Ferris (Stamford, CT: JAI Press, 2001) Vol. 20 pp. 165-197.

23. B. E. Becker, M. A. Huselid, P. S. Pickus and M. F. Spratt, HR as a source of shareholder value: Research and recommendations, Human Resource Management 36 (1997) 39-47.
24. J. Combs, Y. Liu, A. Hall and D. Ketchen, How much do high-performance work practices matter? A meta-analysis of their effects on organizational performance, Personel Psychology 59 (2006) 501-528.

25. N. Khatri, Managing human resource for competitive advantage: A study of companies in Singapore, International Journal of Human Resource Management 11(2) (2000) 336-366.

26. O. C. Richard and N. B. Johnson, Understanding the impact of human resource diversity practices on firm performance, Journal of Managerial Issues 13(2) (2001) 177-195.

27. L. Harris and E. Ogbonna, Strategic human resource management, market orientation, and organizational performance, Journal of Business Research 51(2) (2001) 157-166.

28. I. Vlachos, The effect of human resource practices on organizational performance: evidence from Greece, International Journal of Human Resource Management 19(1) (2008) 74-97.

29. I. Nikandrou and N. Papalexandris, The impact of M\&A experience on strategic HRM practices and organizational effectiveness: Evidence from Greek firms, Human Resource Management Journal 17(2) (2007) 155-177.

30. K. W. Green, C. Wu, D. Whitten and B. Medlin, The impact of strategic human resource management on firm performance and HR professionals' work attitude and work performance, International Journal of Human Resource Management 17(4) (2006) 559-579.

31. T. Bailey, Discretionary effort and the organization of work: employee participation and work reform since Hawthorne, Working paper (Columbia University, New York, 1993).

32. M. A. Youndt, S. A. Snell, J. W. Dean and D. P. Lepak, Human resource management, manufacturing strategy, and firm performance, Academy of Management Journal 39 (1996) 836-866.

33. S. S. Tzafrir, The relationship between trust, HRM practices and firm performance, International Journal of Human Resource Management 16(9) (2005) 1600-1622.

34. A. Verma, Employee involvement in the workplace, in Union-management relations in Canada, eds. $\mathrm{M}$. Gunderson \& A. Ponak (Reading, Massachusetts: Addison-Wesley, 1995) pp. 281-308.

35. A. J. Wagner, Participation's effects on performance and satisfaction: A reconsideration of research evidence, Academy of Management Review 19 (1994) 312-330.

36. D. Guest, N. Conway and P. Dewe, Using sequential tree analysis to search for bundles of HR practices, Human Resource Management Journal 14(1) (2004) 79-96.

37. J.-L. Marichal and M. Roubens, Determination of weights of interacting criteria from a reference set, European Journal of Operational Research 124 (2000) 641-650.

38. M. Grabisch, k-order additive fuzzy measures, in 6 th International Conference on Information Progressing and Management of Uncertainty, Fuzziness and Knowledge Based Systems 5 (1997) 587-607.

39. L. S. Shapley, A Value for n-person games, in Contributions to the Theory of Games, Vol.II, Annals of Mathematics Studies, eds. H. W. Kuhn and A. W. Tucker, 
(Princeton University Press, Princeton, New Jersey, 1953) 28, pp. 307-317.

40. T. Murofushi and S. Soneda, Techniques for reading fuzzy measures (III): Interaction index, in 9th Fuzzy System Symposium, (Sapporo, Japan, 1993), pp.693-696.

41. M. Grabisch, T. Murofushi and M. Sugeno, Fuzzy Measures and Integrals, Fuzzy Measures and Integrals Theory and Applications (Physica-Verlag Heidelberg, New York, 2000).

42. C. A. Bana e Costa and J. C. Vansnick, Sur la quantification des jugements de valeur: L'approche MACBETH, Cahiers du LAMSADE, 117, (Université Paris - Dauphine, Paris, 1993).

43. C. A. Bana e Costa and J. C. Vansnick, MACBETH - An interactive path towards the construction of cardinal value functions, International Transactions in Operational Research 1(4) (1994) 489-500.

44. C. A. Bana e Costa and J. C. Vansnick, The MACBETH approach: Basic ideas, In Proceedings of the International Conference on Methods and Applications of Multi-Criteria Decision Making (FUCAM, Facultés Universitaires Catholiques de Mons, 1997), pp. 86-88.

45. C. A. Bana e Costa and M. P. Chagas, A career choice problem: An example of how to use MACBETH to build a quantitative value model based on qualitative value judgments, European Journal of Operational Research 153 (2004) 323-331.

46. F. Montignac, I. Noirot and S. Chaudourne, Multi-criteria evaluation of on-board hydrogen storage technologies using the MACBETH approach, International Journal of Hydrogen Energy, Article In Press, (2008).

47. M. Roubens, A. Rusinowska and H. de Swart, Using MACBETH to determine utilities of governments to parties in coalition formation, European Journal of Operational Research 172 (2006) 588-603.

48. L. Berrah and V. Clivillé, Towards an aggregation performance measurement system model in a supply chain context, Computers in Industry, 580 (2007) 709-719.

49. C. A. Bana e Costa, C. S. Oliveira and V. Vieira, Prioritization of bridges and tunnels in earthquake risk mitigation using multicriteria decision analysis: Application to Lisbon, Omega 36 (2008) 442-450.

50. C. A. Bana e Costa, J. M. De Corte and J. C. Vansnick, On the mathematical foundations of Macbeth, in Multiple Criteria Decision Analysis: State Of The Art Surveys, eds. J. Figueira, S. Greco and M. Ehrgott (Kluwer Academic Publishers, Dordaecht, 2005), pp. 409-442.

51. V. Clivillé, L. Berrah and G. Mauris, Quantitative expression ans aggregation of performance measurements based on the MACBETH multi-criteria method, International Journal of Production Economics 105 (2007) 171-189.

52. J. Lu, G. Zhang and F. Wu, Team situation awareness using web-based fuzzy group decision support systems, International Journal of Computational Intelligence Systems 1(1) (2008) 50-59. 